"All causes of jaundice." I realize, of course, that these are purely symptomatic diagnoses and include many very varying diseases. The American system, with its insistence on an attempt at exact aetiology, possibly precludes a classification on a symptomatic basis. Is this the kind of grouping that administrators need, or is an aetiological one not as good or better?-I am, etc.,

Ayr.

$$
\text { W. O. G. TAYLOR. }
$$

SIR,-Dr. W. A. Bourne (February 9, p. 330) has found the International Statistical Classification of Diseases, Injuries, and Causes of Death unsuitable for the clinical purposes in which he is interested, and has suggested that the World Medical Association might appropriately consider a combined clinical and statistical system. The international statistical classification, like the obsolete Provisional Morbidity Classification of the Medical Research Council (1944), was not primarily designed either as a nomenclature of diseases or as a diagnostic index for clinical recording and research. For purposes of nomenclature there is already in this country the admirable Nomenclature of Disease of the Royal College of Physicians (7th ed., 1948).

The need for a diagnostic index for clinical purposes, particularly in respect of hospital records, has been recognized by the Registrar-General's advisory committee on medical nomenclature and statistics. The committee considered that the international classification might well form the basis of such a diagnostic index. Accordingly a subcommittee has recently been appointed to examine the possibility of adapting the international classification for this purpose. Already the subcommittee has inquired from a number of hospitals known to be using it how far it has been found suitable as the basis for a diagnostic index, and what adaptations have been found necessary to meet the needs of particular specialties.

It would be of considerable help to the subcommittee if clinicians would bring to my attention any shortcomings of the international classification for the clinical purposes in which they are interested, together with their suggestions for its expansion or modification.-I am, etc.,

General Register Officer,
Somerset House, W.C.2.

W. P. D. Logan,

\section{POINTS FROM LETTERS}

\section{Treatment of Tropical Ulcers}

Dr. T. C. Hallinan (Jamaica, B.W.I.) writes: I was very interested in the article by Dr. H. D. O'Brien (December 29, 1951, p. 1544). I was quoted as having treated 15 cases of small tropical ulcers, and an indefinite number of large ones. In fact, in my original article the only figure I mentioned was a total of 188 cases. In actual fact 87 of these were small ulcers and the remaining 101 were medium (2 to 3 in. $(5$ to $7.5 \mathrm{~cm}$.) diameter) or large $(4$ in. $(10 \mathrm{~cm}$.) or larger). I now have a total of 1,023 cases treated, and my results remain the same, in time of healing, as mentioned in my original article. One thing, however, I did not mention in the article is that almost all of my cases receive ambulant treatment and go about their normal work during the period of treatment, and even my worst cases could resume work within two weeks or less of commencing treatment, with only two exceptions, in whom ulcers involved a large part of the heel and sole of the foot, baring both bone and tendon. These took six weeks before resuming work. The dressings were applied only once a week, preferably one in two weeks, and are very simple in application, not needing a skilled dresser. Thus the loss of man-power and earning capacity on the part of the workers is almost negligible, and there is also great economy in dressings and doctors' time. One other fact has been observed recently-that if no yeast or other form of vitamin-B complex is taken the ulcers take at least half as long again to heal. This supports the theory that these ulcers are basically a nutritional deficiency disease.

\section{Correction}

Owing to a printer's error the word " arthritis " was substituted for "arteritis" in the penultimate line of the letter on diabetic gangrene from W. E. and E. V. Shute in our issue of February 2 (p. 276).

\section{Obituary.}

Sir RICHARD LUCE, K.C.M.G., C.B., F.R.C.S.

We record with regret the death, which took place on February 22, of Major-General Sir Richard Luce, for many years senior surgeon, and later consulting surgeon, to the Derbyshire Royal Infirmary.

Richard Harman Luce was born in 1867 at Malmesbury, Wiltshire, the son of an Army colonel. He went to school at Clifton College, and from there went on to Christ's College, Cambridge, taking the B.A. with firstclass honours in the Natural Sciences Tripos of 1889. In that year he entered as a student at Guy's Hospital, and qualified in 1893 . He proceeded to the degrees of M.A., M.B., B.Ch. in the same year. After a period as house-surgeon and obstetric registrar at Guy's and another housesurgeoncy at York County Hospital, he began surgical practice in the North Midlands, making his home at Derby. He took the F.R.C.S. in 1894.

From 1909 to 1913 he was A.D.M.S., North Midland Division, Territorial Force, and in the war: which began in 1914 he

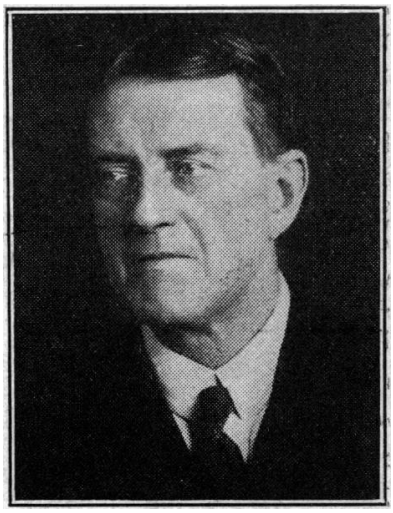

[Press Portran Burean served in Palestine, Gallipoli, and Egypt, becoming, in 1918-19, Director of Medical Services, Egyptian Expeditionary Force, with the rank of major-general. He rendered conspicuous service in the war, was mentioned in dispatches, and was invested with the C.B. (military) in 1916, the C.M.G. in 1918, and the K.C.M.G. in 1919.

In 1924 Sir Richard Luce entered Parliament as Conservative Member for his adopted city of Derby. His election for such a constituency, the stronghold of one of the then leaders of the Labour party, must be ascribed to his personal popularity, for the other Conservative candidate who ran with him for the two-member seat was some thousands below him at the poll. He did quiet but good work in the House of Commons, and was a useful accession to the Parliamentary Medical Committee, but he failed to retain his seat at the next general election in 1929.

In Derby he built up a sound reputation as an operating surgeon, and in addition to his work at the Royal Infirmary, where he was energetic in promoting plans for new buildings, he was surgeon to the Derbyshire Hospital for Sick Children and consulting surgeon to the Ripley and Wirksworth cottage hospitals. He served as medical referee under' the Workmen's Compensation Act in the Derby county court circuit.

For some years Sir Richard Luce had a seat on the Council of the B.M.A., and he gave long and patient service to its Hospitals Committee, of which he was chairman. It fell tó his lot to pilot some large revisions of hospital policy through the meetings of the Representative Body in the early nineteen-thirties, and, although he was not a man who cultivated the platform, he showed quite extraordinary skill, foresight, adaptability, and openness of mind in dealing with a most intricate 